\title{
Pancreaticobiliary Malunion
}

National Cancer Institute

\section{Source}

National Cancer Institute. Pancreaticobiliary Malunion. NCI Thesaurus. Code C121970.

An abnormality of the pancreatic and biliary ducts in which their junction occurs above the duodenal wall. 